\title{
Development and Evaluation of a Controlled Release System of TBH Herbicide Using Alginate Microparticles
}

\author{
Daniela Macedo Faria ${ }^{a}$, Sidney Macias Dourado Júnior ${ }^{a}$, João Pedro Lopes do Nascimento ${ }^{a}$, Eloiza \\ da Silva Nunes ${ }^{a}$, Renata Pereira Marques ${ }^{b}$, Luciana Sgarbi Rossino ${ }^{c, d}$, Jéferson Aparecido Moreto ${ }^{a, e *}$ \\ ${ }^{a}$ Federal Institute Goiano - IF Goiano, Rodovia Sul Goiana Km 01, Zona Rural, Zip code 75.901-970, \\ Rio Verde, GO, Brazil \\ ${ }^{b}$ Rede Arco Norte, Federal Institute Goiano - IF Goiano, Rodovia Sul Goiana Km 01, Zona Rural, Zip \\ code 75.901-970, Rio Verde, GO, Brazil \\ c Sorocaba Technological College - FATEC, Av. Engenheiro Carlos Reinaldo Mendes, 2015, Alto da \\ Boa Vista, Zip code 18013-280, Sorocaba, SP, Brazil \\ ${ }^{d}$ Federal University of São Carlos - UFSCar, Rodovia João Leme dos Santos, Km 110, Bairro do \\ Itinga, Zip code 18.052-780, Sorocaba, SP, Brazil \\ ${ }^{e}$ Institute of Exact Sciences, Naturals and Education, Federal University of Triângulo Mineiro - UFTM, \\ Avenida Doutor Randolfo Borges Júnior, Univerdecidade, Zip code 38.064-200, Uberaba, MG, Brazil.
}

Received: June 10, 2016; Revised: October 17, 2016; Accepted: November 21, 2016

The development of controlled delivery system formulations has received increasing interest in the agriculture area. Tebuthiuron (TBH) is the most commonly used herbicide for weed control in sugar cane and cotton crops. The TBH and some of its metabolites are detected in surface water by leaching process, evidencing contamination and the need for an efficient process to decrease pesticide residues. The development of a controlled system release appears as a good solution. The present investigation aimed to study the development and evaluation of alginate microparticles as a delivery system for the TBH. The calcium alginate microparticles were prepared from the crosslinking of sodium alginate by $\mathrm{Ca}^{++}$containing varied amounts of TBH supplied in $\mathrm{CaCl}_{2}$ aqueous solution. The particle size and morphological analysis of microparticles were determined by optical microscopy (OM) and by field emission gun scanning electron microscopy (FEG-SEM). The encapsulation efficiency and release of TBH studies was accessed by UV-vis spectroscopy. The results show that the polymeric microparticles containing TBH can be obtained successfully through a simple method and is suitable as a controlled release carrier system for herbicides and can be effective for controlling weeds.

Keywords: Biodegradable Polymer, Weed control, Microencapsulation, Controlled release

\section{Introduction}

Agrochemicals have become the product class most widely encountered in surface and subterranean hydrological systems worldwide, due to their extensive use in agriculture and in urban areas ${ }^{1}$. Currently, there is a great concern for environmental preservation, where the contamination of water is one of the major problems of the degradation of the environment by human activity in the world ${ }^{2}$. Several technologies have been proposed in order to minimize the spread of agrochemicals in the environment, among them are nanoparticulate ${ }^{3}$ and microparticulate ${ }^{4}$ systems designed to provide controlled release such class of compounds.

Tebuthiuron (TBH) is one of herbicides most used on sugar cane in the states of São Paulo ${ }^{5}$ and Goiás in Brazil for weed control. TBH is a substituted urea herbicide with chemical name N-[5-1,1-dimethylethyl)-1,3,4-thiadizol-2yl]NN' dimethylurea and molecular structure show in Figure 1. This herbicide is selective recommended for the weed control

* e-mail: jeferson.moreto.uftm @gmail.com in the sugar cane crop and applied in pre-emergence. Some of its metabolites were detected in surface water in the city of Ribeirão Preto, São Paulo, evidencing contamination and the need for an efficient process to remove pesticide residues from the environment ${ }^{6}$.

Controlled release systems have also been applied extensively in the food and pharmaceutical industries for the release of active substances such as nutrients, drugs and $\operatorname{aromas}^{4,7}$. Thus, polymeric microparticles have emerged among the new technologies under study as a potential alternative for the development of release system in agriculture. Silva et al. ${ }^{1}$ studied the paraquat-loaded alginate/chitosan nanoparticles for soil sorption. The results of this survey showed new perspectives for using biopolymer membranes (particularly alginate and chitosan/alginate) for remediation of areas contaminated with herbicides ${ }^{2}$.

According to MIGNON et al. ${ }^{8}$, alginate is a linear copolymer composed of mannuronic and guluronic acid, covalently linked in varying sequences and blocks and is commercially available as a sodium salt (Na-Alg). Interestingly, when 


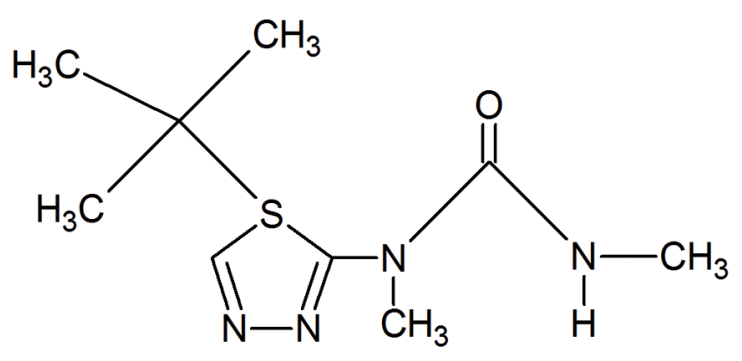

Figure 1: Molecular structure for the THB herbicide.

$\mathrm{NaAlg}$ is combined with multivalent cations such as calcium (originating from salts such as calcium chloride, $\mathrm{CaCl}_{2}$ ), a physically cross-linked network is formed, which becomes insoluble in water. Figure 2 present the chemical structures of Na-Alg and Ca-Alg. Sodium alginate is natural polymer, non-toxic, biodegradable, biocompatible and $\mathrm{pH}$ sensitive 9 . Several works used sodium alginate as encapsulant of protein and living cells due to its good biocompatibility, gelation in mild conditions and a relatively inert matrix. The aim of this work is to prepare and characterize a new delivery system for TBH herbicide using polymeric microparticles of alginate.

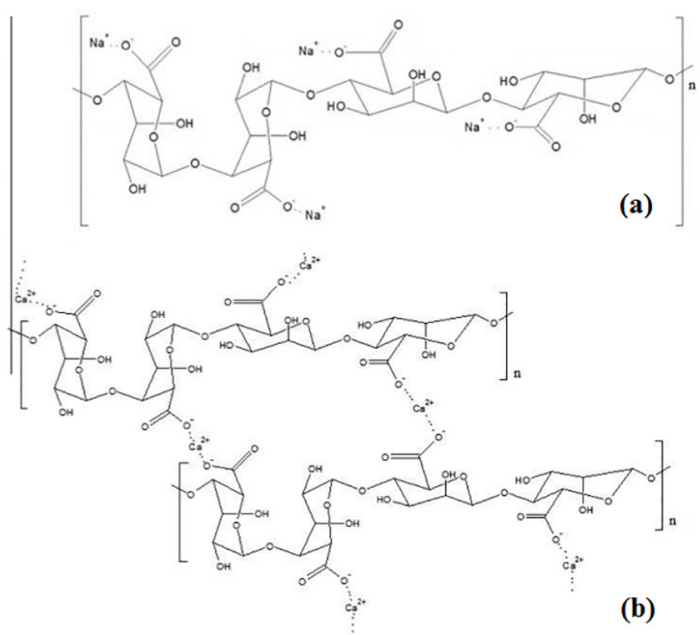

Figure 2: Representation of $\mathrm{Na}^{+}$and $\mathrm{Ca}^{2+}$ ions interacting with alginate chais (a) Na-Alg and (b) Ca-Alg.

\section{Experimental}

\subsection{Materials}

The biopolymer sodium alginate were purchased from Sigma -Aldrich with molecular weight (M/W) of 100.000 g.mol ${ }^{-1}$, viscosity of $15-20 \mathrm{cP}, 61 \%$ of mannuronic acid and $39 \%$ of guluronic acid. To obtain the alginate microparticles we also used calcium chloride, $\mathrm{CaCl}_{2}$ (Sigma - Aldrich), sodium chloride, $\mathrm{NaCl}$ (Sigma - Aldrich) and deionized water (Milli-Q system (Millipore)).
In the present work the commercial herbicide (Combine ${ }^{\circledR}$ ), whose formulation has $500 \mathrm{~g} . \mathrm{L}^{-1}$ of TBH were used for the encapsulation in the alginate microparticles. One of its main features is its long persistence in soil and its high solubility in water $2.500 \mathrm{mg} . \mathrm{L}^{-1}$ to $20{ }^{\circ} \mathrm{C}$. The herbicide analytical grade used was the TBH (PESTANAL ${ }^{\circledR}$ Sigma-Aldrich) with molecular mass $228.31 \mathrm{~g}$. $\mathrm{mol}^{-1}$, whose KOW is 6.17 $\mathrm{X} 10^{01}$ at $\mathrm{pH} 7$ to $20^{\circ} \mathrm{C}$, registered under CAS 34014-18-1. All other materials were at least of analytical grade and used without previous purification.

\subsection{Preparation of bare- and TBH-loaded alginate microparticles}

The apparatus used in this work was built on the basis a scheme presented by Dias et al. ${ }^{10}$ and Shi et al. ${ }^{11}$. Previously, solutions of sodium alginate $(1,2$ and $3 \% \mathrm{~m} / \mathrm{v})$ and concentrations of $0.1,0.3$ and $0.5 \mathrm{~mol} \cdot \mathrm{L}^{-1}$ of $\mathrm{CaCl}_{2}$ were prepared. Subsequently, sodium alginate solution was dropped in $\mathrm{CaCl}_{2}$ solution, resulting in a total of 100 microparticles for each concentration used. After, the microparticles were filtered using a Buchner funnel and cleaned with distilled water. The obtained microparticles were divided in two portions, one was stored in deionized water and the other was dried in oven at $35^{\circ} \mathrm{C}$ for $24 \mathrm{~h}$. The number of microparticles was obtained by counting the number of drops of alginate solution deposited into the $\mathrm{CaCl}_{2}$ solution. Each drop acts as a reactor originating one single microparticle.

In order to improve the texture and roundness of the microparticles the alginate solutions was adjusted to 0.1 $\mathrm{mol} \cdot \mathrm{L}^{-1}$ of sodium chloride and new batches of microparticles were prepared by using the same set of conditions (alginate, $\mathrm{CaCl}_{2}$ concentrations and storage) as described above. The microparticles stored in deionized water passed through a process of water exchange for a period of 3 days. This procedure was adopted in order to withdraw the greatest possible quantity of $\mathrm{NaCl}$ at the calcium alginate microparticles.

For TBH encapsulation into alginate microparticles, desired amounts of combine $\left(4 \mathrm{~g} \cdot \mathrm{L}^{-1}, 6 \mathrm{~g} \cdot \mathrm{L}^{-1}\right.$ and $\left.8 \mathrm{~g} \cdot \mathrm{L}^{-1}\right)$ were added to a freshly prepared $3 \%(\mathrm{~m} / \mathrm{v})$ alginate solution. The TBH-loaded microparticles were obtained by dropping this solution in $0.1 \mathrm{~mol} \cdot \mathrm{L}^{-1} \mathrm{CaCl}_{2}$ and isolated as described above. The encapsulation efficiency of TBH was measured by the amount of herbicide remaining in the supernatant.

\subsection{Characterization of the alginate microparticles}

The dried microparticles of calcium alginate were photographed using a scanner (MFP HP Deskjet Ink Advantage 1516). This procedure can be used to decrease the image distortion as cited by Mendoza-Muñoz et al. ${ }^{12}$.

The dried microparticles of alginate were analyzed by optical microscopy (OM) and scanning electron microscopy 
(SEM). The methodology used to prepare the samples to OM and SEM comprises classic methodologies in the material science area. For SEM analysis the microparticles were affixed on the stub and the sputtering was carried out with $\mathrm{Au}$.

The average diameter of the dried calcium alginate microparticles was measured by digital image analysis and the polydispersity distribution curves were obtained using ImageJ software. A number of 800 calcium alginate microparticles were used to make the polydispersity distribution.

\subsection{TBH release experiments}

Prior to encapsulating the TBH herbicide in the alginate microparticles it was verified by ultraviolet-visible spectroscopy (UV-Vis) technique the absorbance of Combine ${ }^{\circledR}$ herbicide when compared to the active ingredient. Following the same procedure was adopted for combined solution of the commercial herbicide and sodium alginate. For this, we used a spectrophotometer PerkinElmer Lambda 750 in the range $200-800 \mathrm{~nm}$. The determination of TBH concentration to calculate the encapsulation efficiency and the release experiments was performed by monitoring the absorbance of TBH at $253 \mathrm{~nm}$.

The TBH analytical curve was obtained by preparing aqueous solutions of TBH analytical grade varying the herbicide concentration from $0.0008 \mathrm{~g} . \mathrm{L}^{-1}$ to $0.02 \mathrm{~g} . \mathrm{L}^{-1}$ and then measuring the absorbance at $253 \mathrm{~nm}$. The absorbance versus concentration data was adjusted using a minimumsquare method to obtainment of the best fit as can be seen in Figure 3.

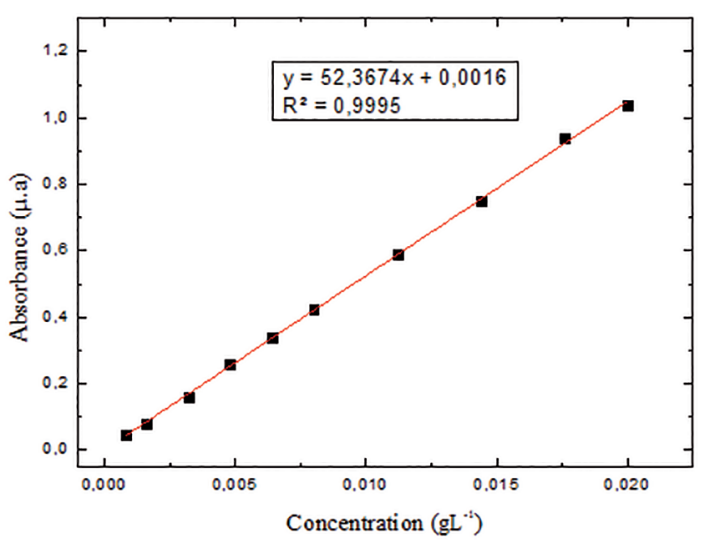

Figure 3: Analytical curve obtained by preparing aqueous solutions of TBH herbicide.

For the controlled release experiment, $40 \mathrm{mg}$ of dried TBH-loaded alginate microparticles were mixed with $20 \mathrm{~mL}$ of deionized water in an Erlenmeyer and let stand at room temperature. The initial $\mathrm{pH}$ was 5.5 and did not change significantly during the course of the experiment. Aliquots of $2 \mathrm{~mL}$ were withdrawn from the solution previously homogenized at different time intervals: $5,10,15,20,30$, $60,120 \mathrm{~min}$ and after the first hour the removal was realized once per hour. After each removal, the same volume was replaced with deionized water.

All release assays was performed in dilution conditions. The encapsulation efficiency (\% EE) was evaluated by the difference of the amount of herbicide added in the alginate + TBH solution and the unentrapped amount of TBH remaining in the supernatant after the removal of the formed microparticles, following the equation:

$\% \mathrm{EE}($ encapsulation efficiency) $=$

[(TBH added - free unentrapped TBH $) /$ THB added $] * 100 \%$ (1)

\subsection{Mathematical models}

To understand the agrochemical release system, mathematical models were used in the present work. To analyze the controlled release behavior of the TBH herbicide from the alginate microparticles the Korsmeyer-Peppas, Higuchi, Baker -Lonsdale, Weibull and Hopfenberg models were performed. Follows a brief description of each mathematical models used in this study:

- Korsmeyer-Peppas model: The Korsmeyer-Peppas mode $1^{13}$ is described by:

$$
\frac{M_{t}}{M_{\infty}}=K t^{n}
$$

Where, $M_{t} / M_{\infty}$ is the proportion of compound released in the time $\mathrm{t}, \mathrm{K}$ is the kinetic constant, and $n$ is the exponent which reflects the type of release mechanism. The KorsmeyerPeppas proposed that values of $n \leq 0.43$ are indicative of release mechanisms that follow Fick's law. The Fick's law, which were developed by Adolf Fick in the $19^{\text {th }}$ century relates that the molar flux due to diffusion is proportional to the concentration gradient (First law) and the rate of change of concentration at a point in space is proportional to the second derivate of concentration with space (second law). The first law in a modern mathematical form can be write as:

$$
N_{i}=-D \nabla C_{i}
$$

Where for species $\mathrm{i}, \mathrm{N}_{\mathrm{i}}$ is the molar flux $\left(\mathrm{mol} \cdot \mathrm{m}^{2} . \mathrm{s}^{-1}\right), \mathrm{D}_{\mathrm{i}}$ is the diffusion coefficient $\left(\mathrm{m}^{2} \cdot \mathrm{s}^{-1}\right)$, and $\mathrm{C}_{\mathrm{i}}$ is the concentration $\left(\mathrm{mol} \cdot \mathrm{m}^{-3}\right)$.

The Fick's second law can be represented as:

$$
\frac{\partial c_{i}}{\partial_{t}}=D_{i} \nabla^{2} C_{i}
$$

In this case, we can assume that $\mathrm{D}_{\mathrm{i}}$ is a constant, which is only true for dilute solution. While, $n>0.85$ (equation 1) indicates that the mechanism are governed by relaxation processes of the polymeric matrix, defined as case II type transport. Intermediate values $0.43 \leq n \leq 0.85$ suggest anomalous behavior with non-Fickian release (combination of diffusion and relaxation of the polymeric matrix). 
- Higuchi Model: The Higuchi Model is based on the quantification of drug release derived from a very simple equation as described below:

$$
f_{t}=\left(K_{h}\right)(t)^{1 / 2}
$$

As can be seen, Higuchi Model describes the release of the $\mathrm{TBH}$ herbicide as the square root of time based on the Fickian diffusion. Where $\mathrm{K}_{\mathrm{H}}$ is the constant reflecting the design variable of the system ${ }^{14}$.

- Baker-Lonsdale Model: This model was developed by Baker and Lonsdale (1974) from the Higuchi model and described the drug release from spherical matrices ${ }^{15}$. Equation 6 has been used to the linearization of release data from several formulations of microcapsules or microspheres.

$$
\frac{3}{2}\left[1-\left(1-\frac{M_{t}}{M_{\infty}}\right)^{2 / 3}\right] \frac{M_{t}}{M_{\infty}}=K_{t}
$$

\section{Where:}

$\mathrm{M}_{\mathrm{t}}$ is the drug release amount at time $\mathrm{t}$

$\mathrm{M}_{\infty}$ is the amount of drug released at an infinite time

$\mathrm{K}$ is the release constant which corresponds to the slope of the graph when plotted as $\left[d\left(M_{t} / M_{\infty}\right)\right] / d t$ with respect to the root of time inverse.

- Weibull Model: This model has been described for different dissolution processes as described by the equation 7 . Weibull model also has two constants, a (time factor) and b (related to the shape of the release curve). The constant $\mathrm{b}$ can be correlated to the exponent $n$ of Korsmeyer-Peppas model.

$$
M=M_{0}\left[1-e^{-\frac{(t-T)^{b}}{a}}\right]
$$

In this equation, $\mathrm{M}$ is the amount of drug dissolved as a function of time $t, M_{0}$ is total amount of drug being released and $\mathrm{T}$ accounts for the lag time measured as a result of the dissolution process.

- Hopfenberg model: The mathematical model developed by Hopfenberg correlates the release of active compound from surface-eroding devices with several geometries as flat, cylindrical and spherical. The Hopfenberg model can be described by equation 8 .

$$
\frac{M_{t}}{M_{\infty}}=1-\left[1-k_{0} t / C_{L} a\right]^{n}
$$

According to SUVAKANTA et al. ${ }^{15}, \mathrm{k}_{0}$ is the zero order rate constant describing the polymer degradation (surface erosion) process, $\mathrm{C}_{\mathrm{L}}$ is the initial drug loading throughout the system, a is the systems half thickness and $n$ is an exponent that varies with geometry.

\section{Results and discussion}

Figure 4 shows the OM images of calcium alginate microparticles for 2 and $3 \%(\mathrm{~m} / \mathrm{v})$ concentrations of sodium alginate. It is important to mention that the $1 \%(\mathrm{~m} / \mathrm{v})$ concentration of sodium alginate did not lead to obtaining of microspheres. As can be seen by optical microscopy the best results were obtained at 3\% alginate using 0.1 mol.L $\mathrm{L}^{-1}$ $\mathrm{CaCl}_{2}$ concentration, since, there was no tail formation. The results obtained in this work corroborate with the studies carried out by Strand et al. ${ }^{16}$ and Burey et al. ${ }^{17}$. According to the authors the best microspheres are obtained with higher sodium alginate concentrations ${ }^{13,17}$.

Figure 5 presents OM images of calcium alginate microparticles with sodium chloride. According MCCONAUGHY et al. ${ }^{18}$ and STRAND et al. ${ }^{16}$ the presence of $\mathrm{NaCl}$ promotes a significant increase of the ionic force, leading to lowering values of zeta potential. In order, to verify the influence of $\mathrm{NaCl}$ on the alginate microparticles the last procedure was carried out in $3 \%(\mathrm{~m} / \mathrm{v})$ of alginate using $0.1 \mathrm{~mol} . \mathrm{L}^{-1} \mathrm{CaCl}_{2}$. It was observed that the addition of $\mathrm{NaCl}$ promoted the formation of regular microparticles and suitable distribution of sizes. In addition, it was observed that the presence of $\mathrm{NaCl}$ promoted an increase in the diameter of the microparticles. Probably the drop sphericity is caused by increased interfacial tension.

Figure 6 presents the polydispersity curve of dried alginate microparticles $(3 \% \mathrm{~m} / \mathrm{v}$ of alginate) with and without $\mathrm{NaCl}(0.1 \% \mathrm{~m} / \mathrm{v})$ using $0.1 \mathrm{~mol} \cdot \mathrm{L}^{-1} \mathrm{CaCl}_{2}$. As can be seen, the alginate microparticles with $\mathrm{NaCl}$ showed a narrow polydispersive curve when compared to alginate microparticles without $\mathrm{NaCl}$. The medium radius of the alginate microparticles with $\mathrm{NaCl}$ presented $4.75 \%$ higher than alginate microparticles without $\mathrm{NaCl}$. On the other hand, the medium circumference of alginate microparticles with $\mathrm{NaCl}$ showed about $8 \%$ better results when compared to microparticles without $\mathrm{NaCl}$. Thus, the addition of $\mathrm{NaCl}$ during the alginate microparticles preparation appears as a critical parameter that should be considered to improve the uniformity of the microparticles. SEM micrographs of calcium alginate microparticles for 2 and $3 \%(\mathrm{~m} / \mathrm{v})$ concentrations of sodium alginate in different concentrations of $\mathrm{CaCl}_{2}$ are shown in Figure 7. The SEM micrographs of calcium alginate microparticles for $3 \%(\mathrm{~m} / \mathrm{v})+0.1 \mathrm{~mol} . \mathrm{L}^{-1} \mathrm{CaCl}_{2}+$ $\mathrm{NaCl}$ are present in Figure 8.

Figure 9 show images obtained by optical microscope of the alginate microparticles prepared in the presence of $\mathrm{NaCl}$ and different concentrations of herbicide, named as: 4, 6 and 8 g.L. . $^{-1}$ Figure 10 presents the polydispersity curves of dried alginate microparticles prepared with $\mathrm{NaCl}$ for different concentration of herbicide. The analysis of the polydispersity curves for the different concentrations of herbicide showed the influence of concentration in the quality of the microparticles. The medium circumferences of dried alginate microparticles + herbicide $+\mathrm{NaCl}$ were (e.g. $0.8299 \mathrm{~mm}$ for 4 g.L. ${ }^{-1}, 0.8395 \mathrm{~mm}$ for 6 g.L $\mathrm{L}^{-1}$ and $0.8137 \mathrm{~mm}$ for $8 \mathrm{~g} . \mathrm{L}^{-1}$.

The SEM micrographs were analyzed to determine and compare the size distribution profiles of the different calcium 


\section{Alginate 2\% \\ 0.1 mol.L ${ }^{-1} \mathrm{CaCl}_{2}$}

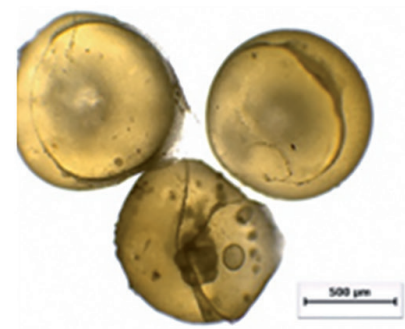

(a)

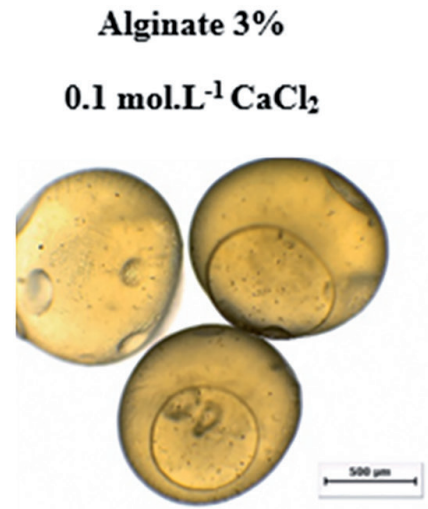

(d)

\section{Alginate 2\% \\ 0.3 mol. $\mathrm{L}^{-1} \mathrm{CaCl}_{2}$}

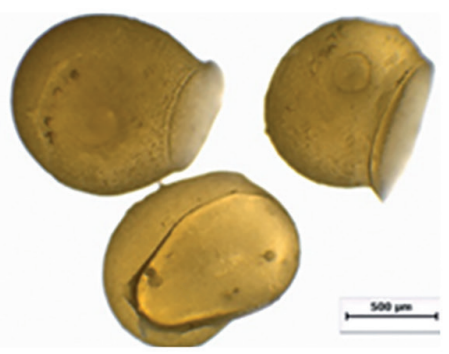

(b)

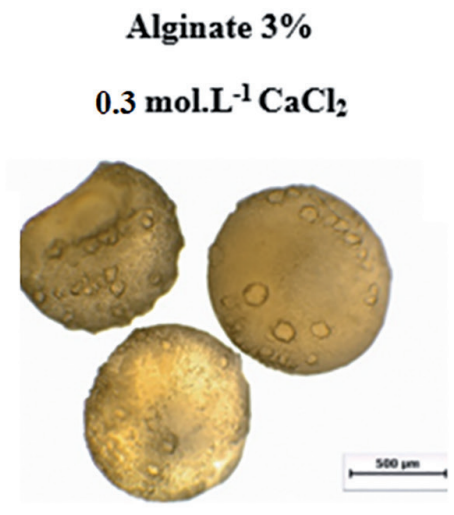

(e)

\section{Alginate 2\% \\ 0.5 mol.L $^{-1} \mathrm{CaCl}_{2}$}

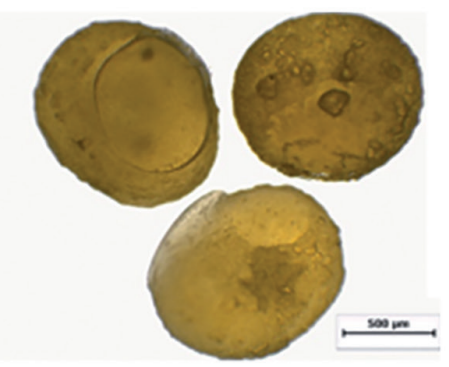

(c)

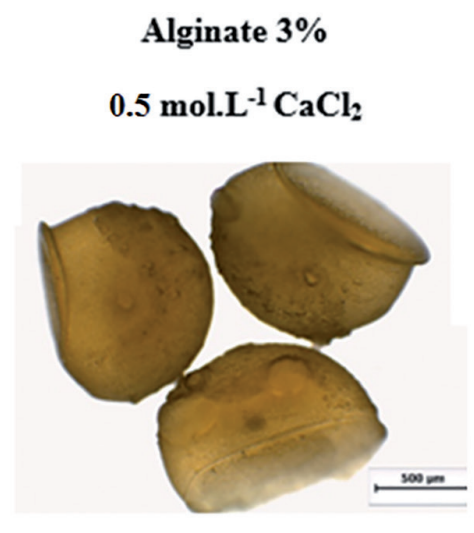

(f)

Figure 4: Images obtained by optical microscopy of dried alginate microparticles at different concentrations of $\mathrm{CaCl}_{2}$.

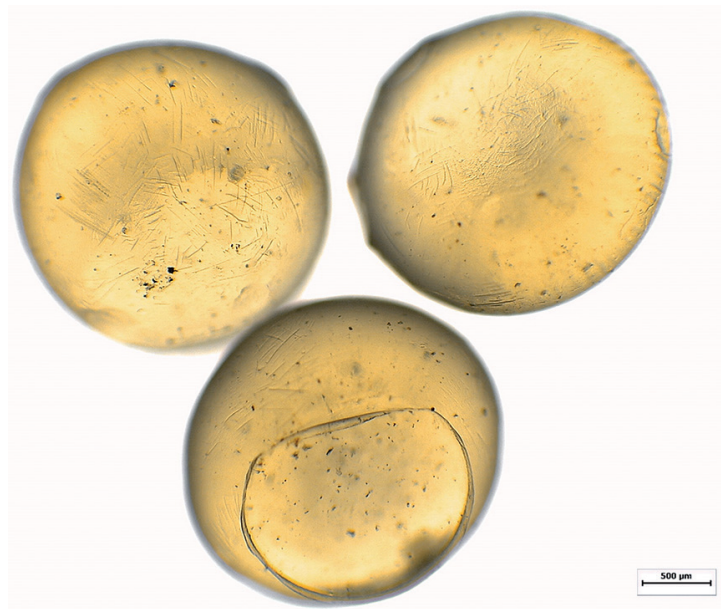

Figure 5: Images obtained by optical microscopy of dried alginate microparticles at $3 \%$ alginate $+0.1 \mathrm{~mol} \cdot \mathrm{L}^{-1} \mathrm{CaCl}_{2}+\mathrm{NaCl}$.

alginate microparticles. Figure 11 shows representative SEM images used for determining the size distribution of the calcium alginate with and without TBH herbicide. It can be noted that the microparticles are spherical with rough surfaces. According to AGRAWAL et al. ${ }^{19}$ spherical with rough surfaces are typical characteristics of microparticles consisting of sodium alginate. According to LACERDA et $a l .{ }^{9}$ the ionic gelation method produces microparticles with large radius from 550 to $650 \mu \mathrm{m}$. In this study, the medium radius of the dried alginate microparticles with $\mathrm{NaCl}$ in different concentrations of $\mathrm{TBH}$ herbicide were $504 \mu \mathrm{m}$ for $4 \mathrm{~g} / \mathrm{L}, 561 \mu \mathrm{m}$ for $6 \mathrm{~g} / \mathrm{L}$ and $599 \mu \mathrm{m}$ for $8 \mathrm{~g} / \mathrm{L}$. The results of EDX analysis at the point $\mathrm{Z} 1$ and $\mathrm{Z} 2$ for the alginate microparticles in Figure 10 show the presence of $\mathrm{C}, \mathrm{O}, \mathrm{Na}, \mathrm{Cl}$ and $\mathrm{Ca}$.

The encapsulation efficiency (\%) was evaluated by the difference of the amount of herbicide initially present in the alginate $+\mathrm{TBH}$ solution and the remaining amount of $\mathrm{TBH}$ in the supernatant after the removal of the formed microparticles. The concentration of TBH was determined by UV-Vis spectroscopy. The encapsulation percentages were: $92 \%$ for the $4 \mathrm{gL}^{-1}, 89 \%$ for $6 \mathrm{gL}^{-1}$ and $86 \%$ for 8 $\mathrm{gL}^{-1}$ microparticles. 


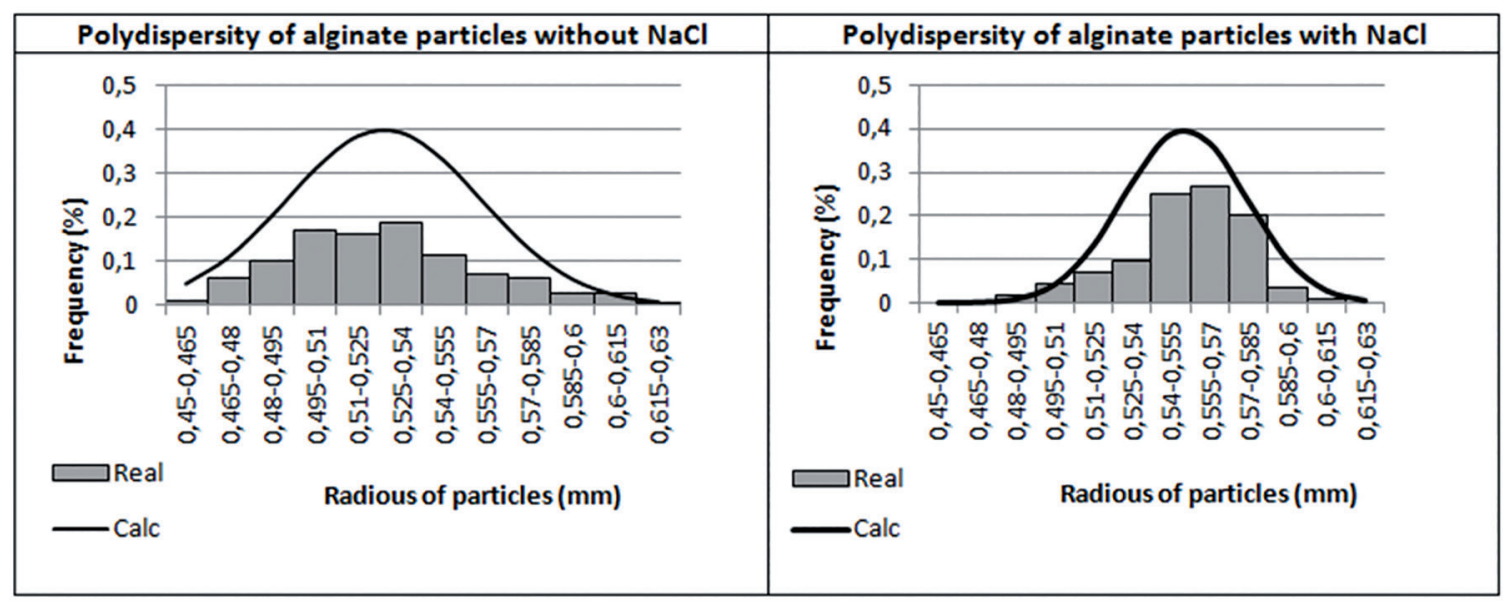

(a)

(b)

Figure 6: Polydispersity curve of dried alginate microparticles (a) without and (b) with $\mathrm{NaCl}$.

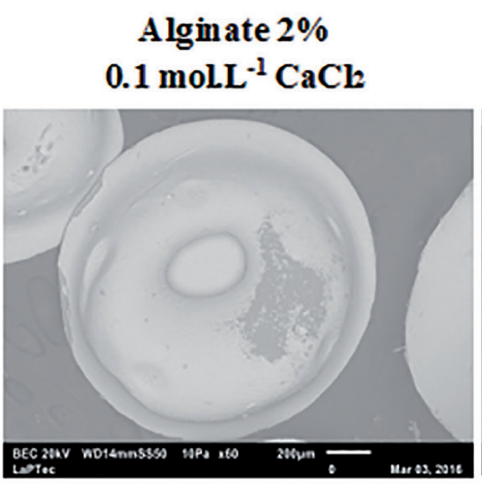

(a)

Alginate 3\% 0.1 mol. $^{-1} \mathrm{CaCl}_{2}$

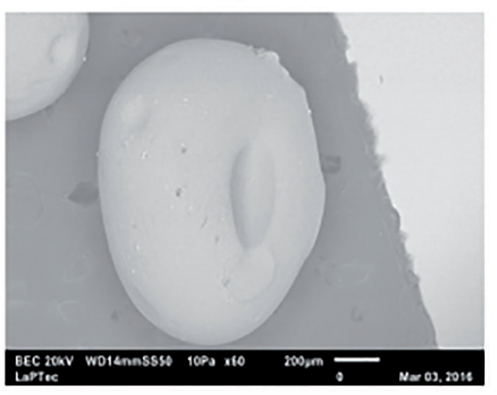

(d)

\section{Alginate 2\% $0.3 \mathrm{molL}^{-1} \mathrm{CaCl}$}

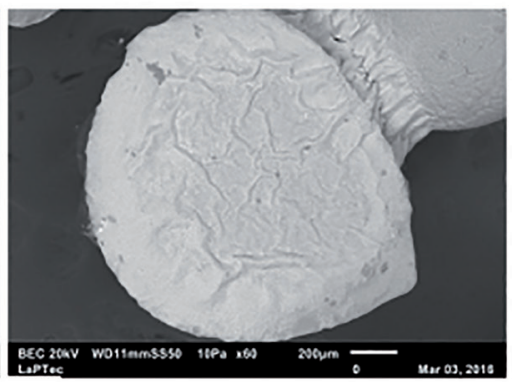

(b)

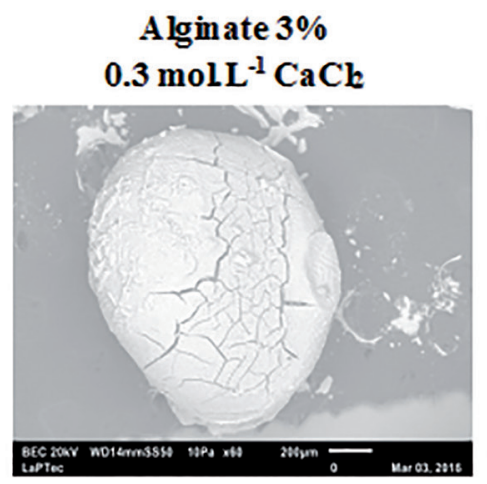

(e)

\section{Alginate 2\% $0.5 \mathrm{molL}^{-1} \mathrm{CaCl}$}

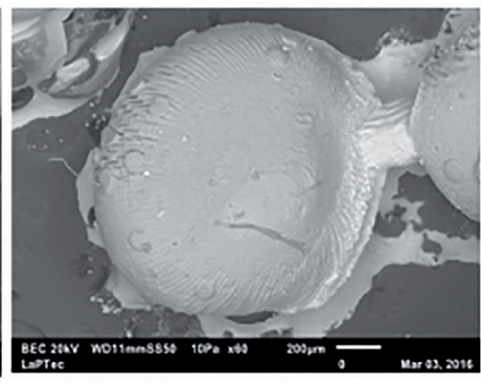

(c)

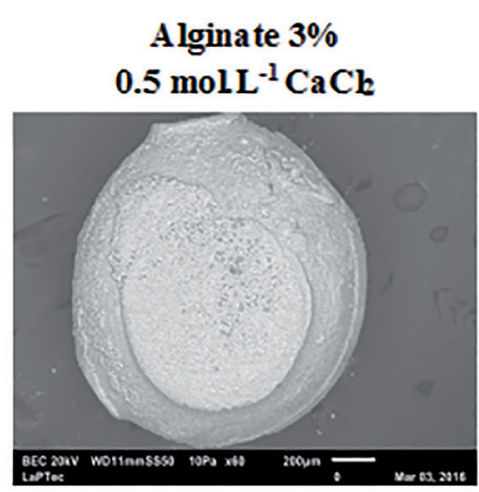

(f)

Figure 7: SEM micrographs of calcium alginate microparticles for different concentrations of $\mathrm{CaCl}_{2}$ and alginate.

The electronic spectra of TBH analytical standard with Combine ${ }^{\circledR}$ solution at the same concentration of $\mathrm{TBH}$ were compared. As result, the two spectra superimposed in the whole range analyzed and exhibit a single band with maximum absorbance at $253 \mathrm{~nm}$ as can be seen in (Figure 12 (a)). This band can be attributed to a $\pi \rightarrow \pi^{*}$ transition in organic compounds with conjugated doubled bonds ${ }^{20}$ and was used to monitor the TBH concentration in Combine ${ }^{\circledR}$ solutions. The obtained analytical curve presents 12 points, in the concentration range from $0.0008 \mathrm{gL}^{-1}$ to $0.02 \mathrm{gL}^{-1}$ of TBH with correlation coefficient $\left(\mathrm{R}^{2}\right) 0.995$. 


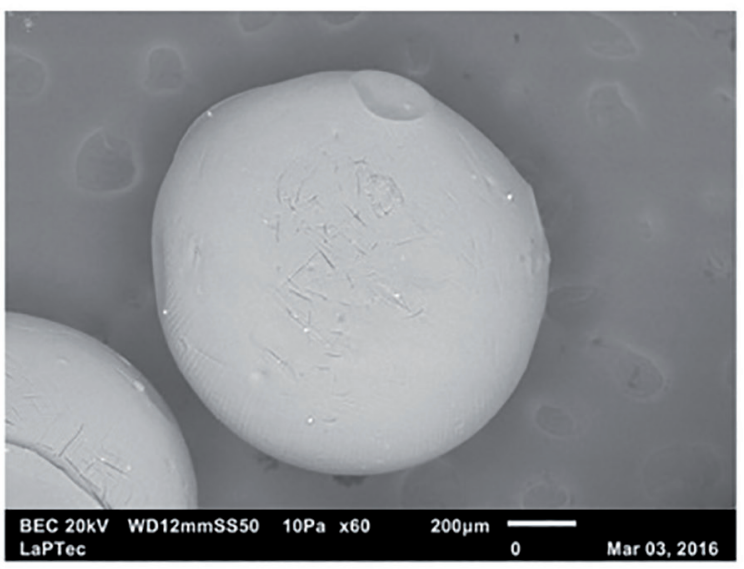

(a)

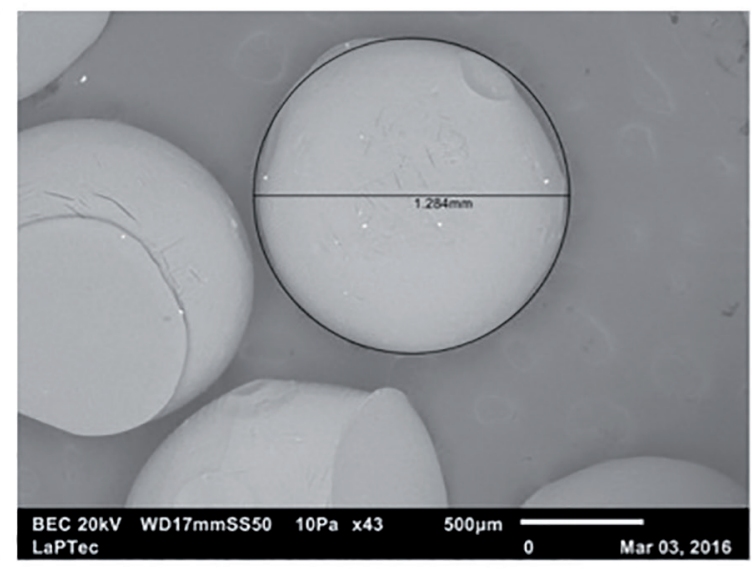

(b)

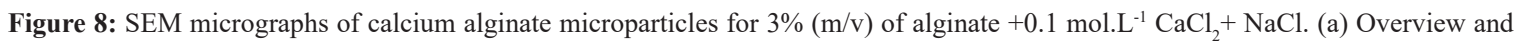
(b) measurement of the diameter.

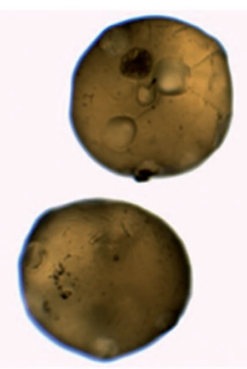

(a)

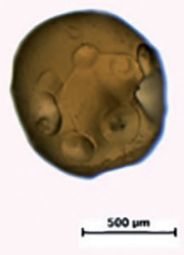

(b)

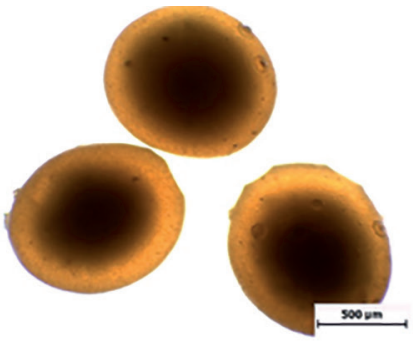

(c)

Figure 9: Images obtained by optical microscopy of dried alginate microparticles at different concentrations of herbicide (a) Alginate 3\% $+\mathrm{NaCl}+$ Herbicide 4 g.L $\mathrm{L}^{-1}$ (b) Alginate $3 \%+\mathrm{NaCl}+$ Herbicide 6 g.L $\mathrm{L}^{-1}$ (c) Alginate $3 \%+\mathrm{NaCl}+$ Herbicide 8 g.L. $\mathrm{L}^{-1}$.

As can be seen in Figure 12 (b) the remaining concentration of alginate in solution in contact with the microparticles do not influenced in the electronic spectra in the range considered for TBH and Combine ${ }^{\circledR}$ analysis. Figure 13 (a) presents the results of release assays, comparing the kinetic profiles of encapsulated TBH in calcium alginate microparticles at ambient temperature for different concentrations of herbicide. Analysis of the release kinetics curves indicated that Combine ${ }^{\circledR}$ was released much more rapidly for $4 \mathrm{gL}^{-1}$ herbicide concentration ( $50 \%$ of release during the first 140 $\mathrm{min})$. Thus, the difference observed between the release profiles of encapsulated herbicide could be explained by the structural characteristics of the microparticles ?

As reported by GRILLO et al. ${ }^{7}$ the herbicide release profile curves were analyzed to obtain information on the possible mechanisms governing the release process. In this work we found that the alginate microparticles showed a slow and sustained release profile. The results of the analyses of calcium alginate microparticles containing Combine ${ }^{\circledR}$ were compared by different mathematical models. The criteria used to determine the best model was based on the correlation coefficient $\left(\mathrm{R}^{2}\right)$. To define the best model it was necessary to analyze each sample dissolution results using various mathematical equations and linear regression. The mathematical model to present higher value of " $\mathrm{R}$ " " is the most suitable for each sample.

The results showed that only $4 \mathrm{~g} . \mathrm{L}^{-1}$ herbicide concentration was adjusted by Korsmeyer-Peppas model. The rate as a function of time $\left(\mathrm{t}^{\mathrm{n}-1}\right)$, the release constant $\mathrm{K}=0.41 \mathrm{~min}^{-1}$, correlation coefficient $R^{2}=0.97$ and diffusion exponent $n$ $=0.49$ were found for the $4 \mathrm{~g} \cdot \mathrm{L}^{-1}$ herbicide concentration, see Figure 13 (b). According to CARBINATTO et al. ${ }^{21}$, the correlation between release exponent $(n)$ values for the Korsmeyer-Peppas equation and drug release mechanisms depending on the geometry shape and for the sphere particle form $0.43<n<0.85$.

The release of TBH from alginate microparticles followed anomalous behavior with non-Fickian release, where the release is controlled by combination of diffusion and relaxation of the polymeric matrix. As reported by 

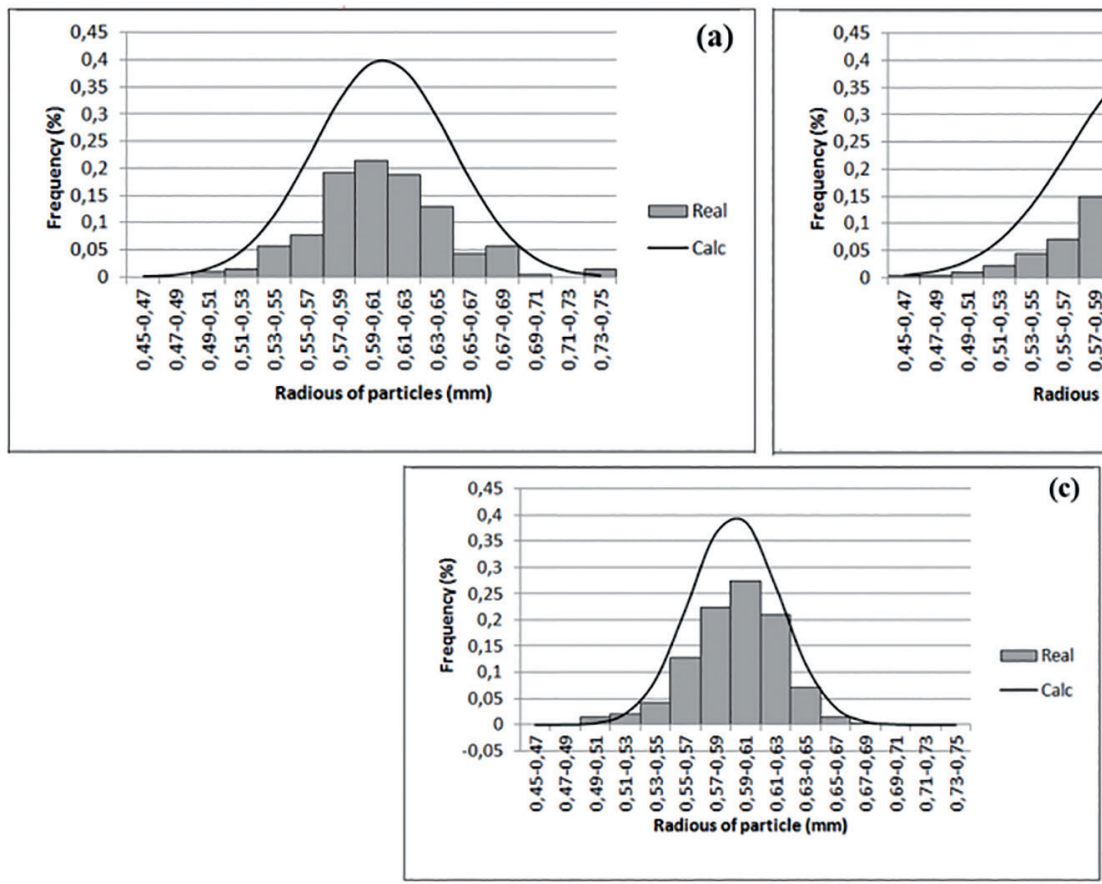

Figure 10: Polydispersity curves of dried alginate microparticles with $\mathrm{NaCl}$ for different concentration of herbicide. (a) 4 g.L. ${ }^{-1}$ herbicide concentration (b) 6 g.L. ${ }^{-1}$ herbicide concentration and (c) 8 g.L. $\mathrm{L}^{-1}$ herbicide concentration.

\section{CAHYANINGRUM; HERDYASTUTI and QOMARIAH ${ }^{22}$} this indicate that the release mechanism of drug is through mechanism combination of erosion and diffusion.

For the $6 \mathrm{~g} . \mathrm{L}^{-1}$ herbicide concentration the best result was obtained using Higuchi model. The Higuchi model suggests that the agrochemical release by diffusion. A graph is plotted between the square root of time taken on $\mathrm{X}$-axis and the cumulative percentage of drug release on $y$-axis and it gives a straight line. Correlation coefficient $\left(\mathrm{R}^{2}>0.99\right)$ indicates that the herbicide release followed the Higuchi equation. The data obtained were plotted as cumulative percentage herbicide release versus square root of time as can be seen in Figure 13 (c).

All the models used before were not sufficient to describe the behavior of the $8 \mathrm{~g} . \mathrm{L}^{-1}$ herbicide concentration. However, the release mechanism can be described by $\mathrm{M}_{\mathrm{t}} \mathrm{M}_{\text {infinite }}=(2 / 3)$ $\mathrm{xt}^{0.2}$ equation for the first $20 \%$ of herbicide released as can be seen in Figure 13 (d). The correlation coefficient is $\mathrm{R}^{2}$ $=0.96$. It is very important to note the results obtained in this survey show the new carrier system has the potential to reduce detrimental effects of the herbicide and can be used for weed control. Table 1 presents all the parameters obtained from each model for the different concentrations of herbicide.

\section{Conclusions}

In this work we studied the controlled system release of TBH herbicide using microparticles of alginate. The conclusions of this study are:

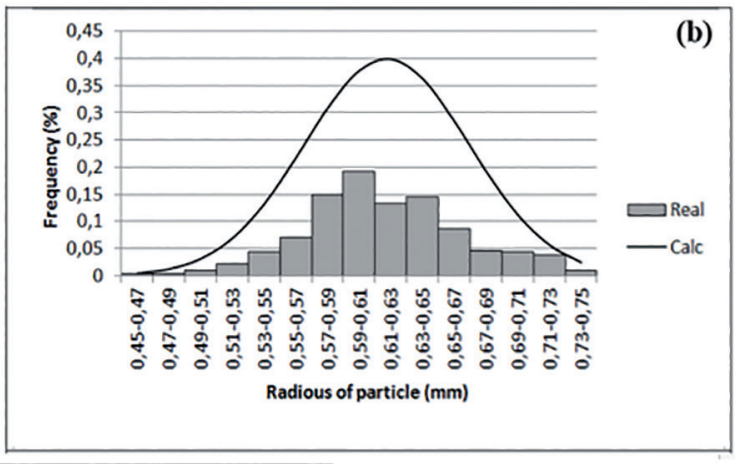

(c)

- Polymeric microparticles containing TBH were obtained successfully through a simple method. Based on the performed tests, it was found that the drip is suitable for the formation of alginate microparticles;

- The OM and SEM techniques demonstrated the strong influence of sodium chloride on the alginate microparticles morphology;

- The addition of $\mathrm{NaCl}$ promoted an increase in the diameter of the microparticles confirming the formation of regular microparticles and suitable distribution of sizes;

- The Korsmeyer-Peppas mathematical modeling revealed anomalous behavior with non-Fickian release (combination of diffusion and relaxation of the polymeric matrix) for the 4 g. $\mathrm{L}^{-1} \mathrm{TBH}$ concentration;

- The Higuchi equation was used to describe the release mechanism for the $6 \mathrm{~g} . \mathrm{L}^{-1}$ herbicide concentration;

- The alginate microparticles presented high encapsulation efficiency of TBH herbicide and are potential candidates for controlled release platforms in agricultural applications;

- These results demonstrate that the structure of kinetic properties of alginate microparticles is suitable as a controlled release carrier system for herbicides and can be effective for controlling weeds.

- The release of the Combine ${ }^{\circledR}$ herbicide occurred faster in the concentration of 4 g. $\mathrm{L}^{-1}$. 


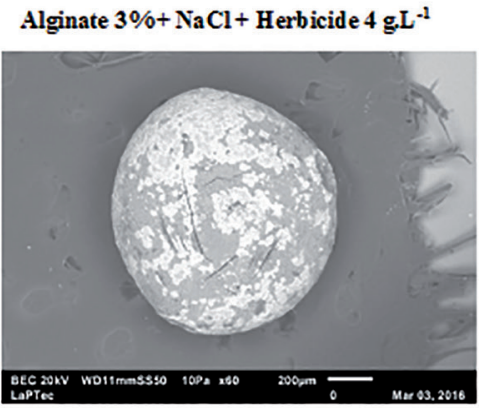

(a)

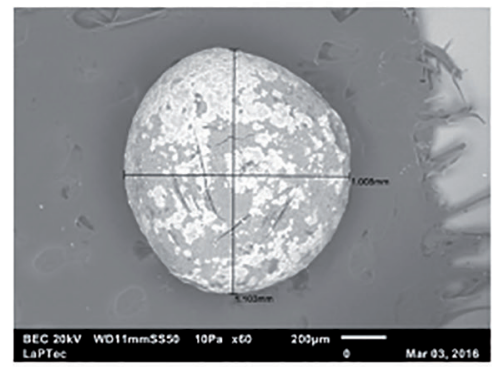

(d)

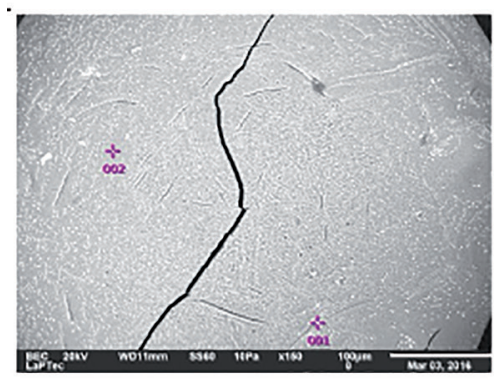

(g)

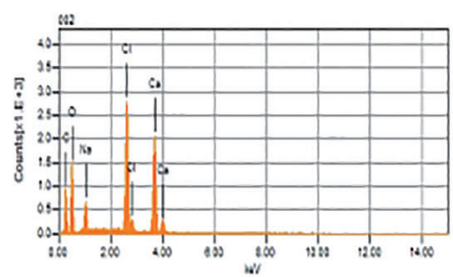

(j)

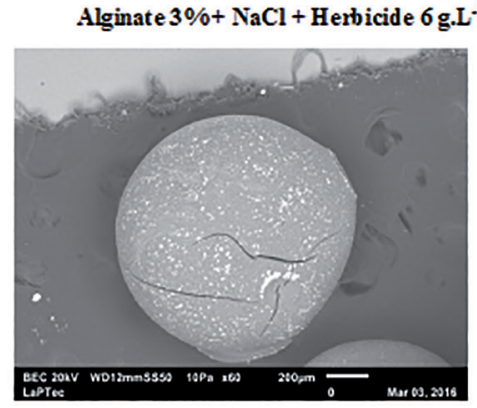

(b)

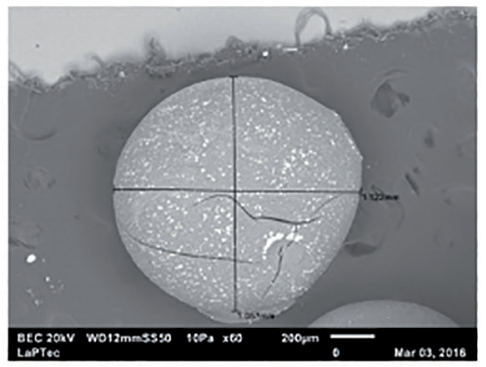

(e)

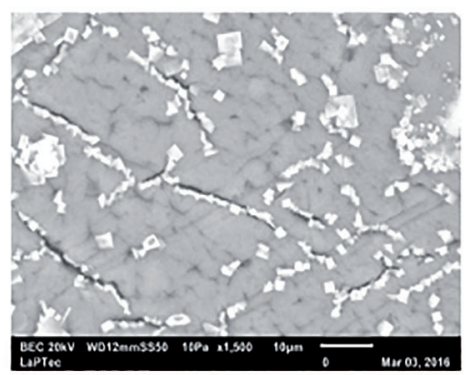

(h)

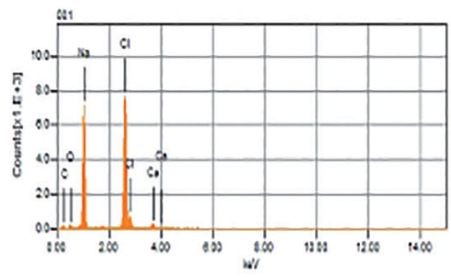

(k)
Alginate $3 \%+\mathrm{NaCl}+$ Herbicide $8 \mathrm{gL}^{-1}$

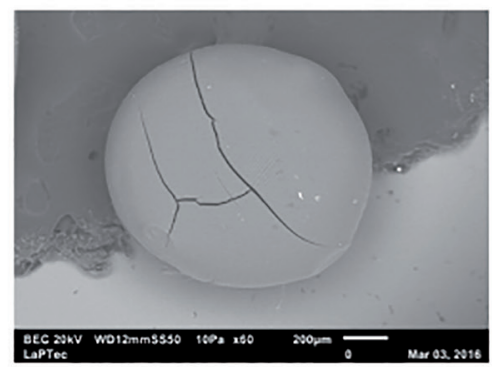

(c)

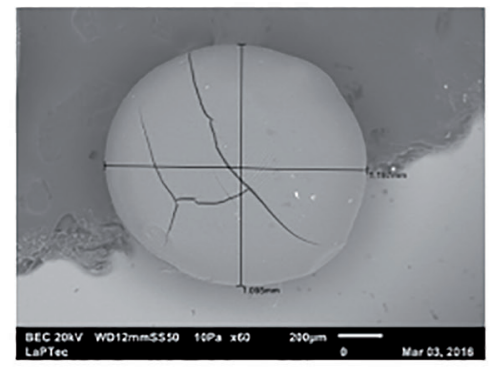

(f)

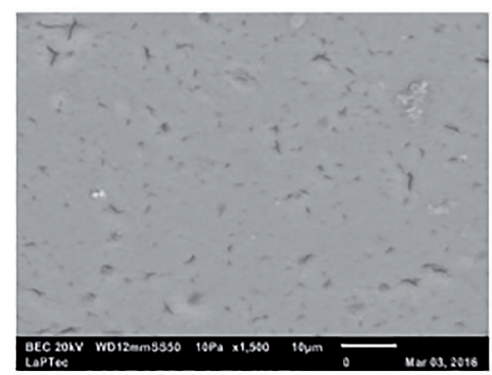

(i)

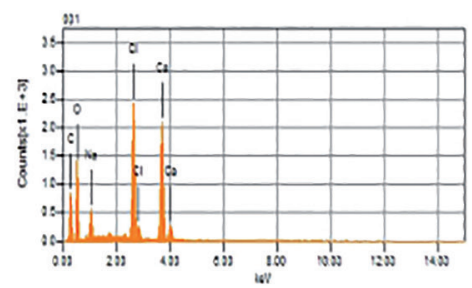

(l)

Figure 11: SEM micrographs and EDX spectra of calcium alginate microparticles for 4 g.L.-1 herbicide concentration, 6 g.L. $L^{-1}$ herbicide concentration and 8 g.L $\mathrm{L}^{-1}$ herbicide concentration.

\section{Acknowledgements}

The authors gratefully acknowledge the Federal Institute Goiano (IF Goiano), Laboratory of Plasma Technology (LaPTec), State University of São Paulo (UNESP) for providing the laboratories facilities and Institute of Exact Sciences, Naturals and Education, Federal University of Triângulo Mineiro (UFTM). The research was financially supported by the Support Foundation of the State of Goiás (FAPEG). 


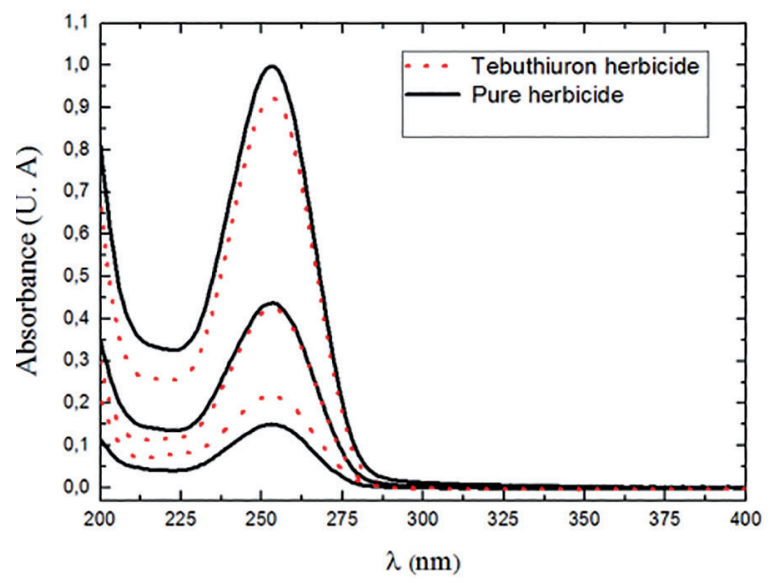

(a)

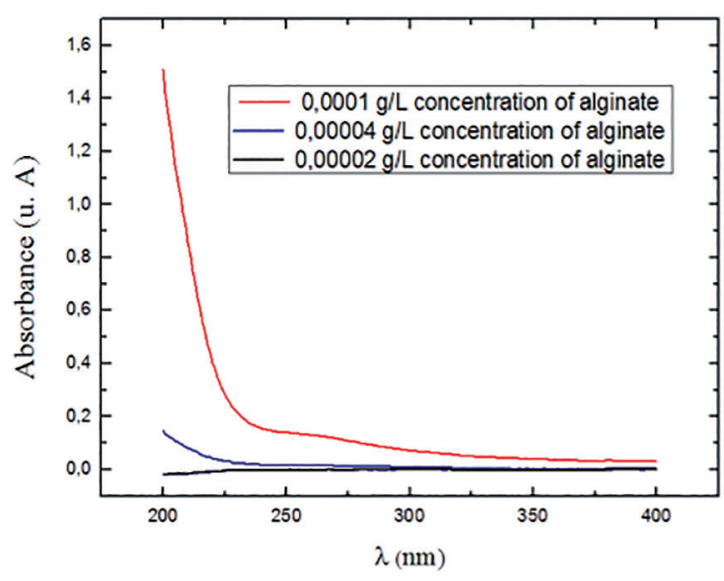

(b)

Figure 12: (a) Spectra of tebuthiuron (TBH) analytical standard and a Combine $\mathrm{C}^{\mathbb{B}}\left(500\right.$ g.L $\mathrm{L}^{-1}$ of TBH) solutions and (b) spectra of alginate in different concentrations.

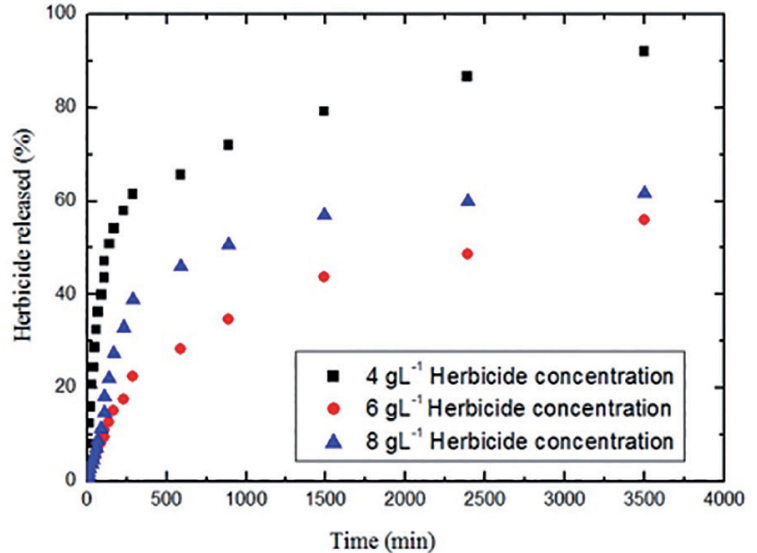

(a)

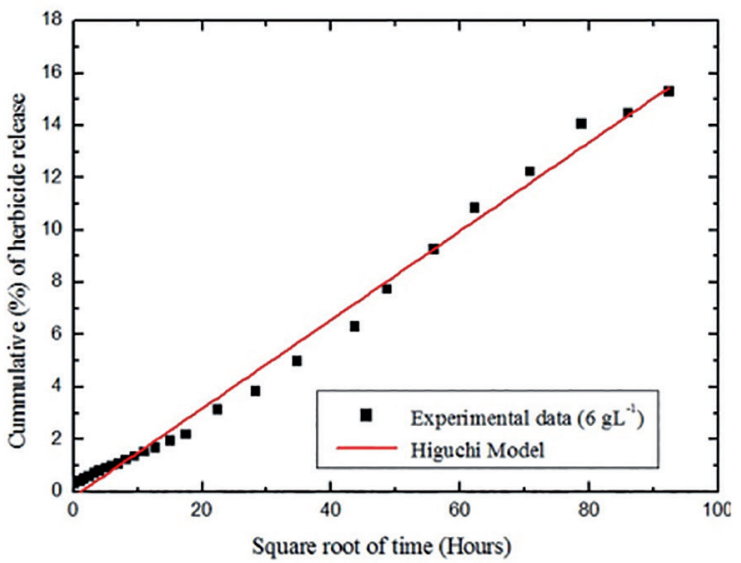

(c)

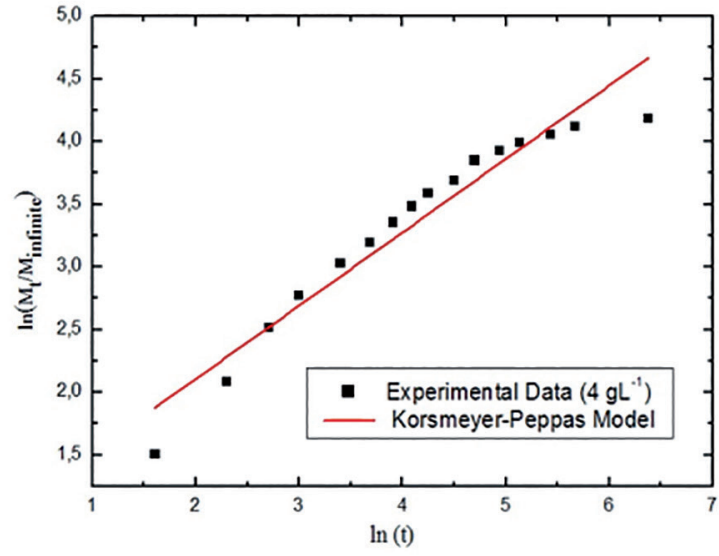

(b)

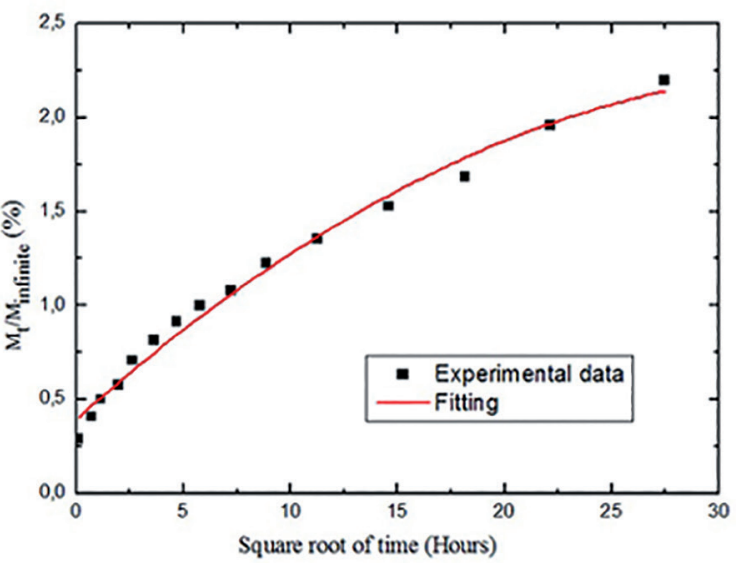

(d)

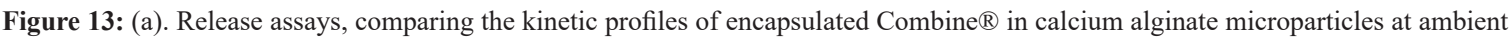
temperature for different concentrations of herbicide. (b). Mechanism of herbicide release by Korsmeyer-Peppas model for the 4 g.L-1 herbicide concentration. (c). Mechanism of herbicide release by Higuchi model for the 6 g.L $L^{-1}$ herbicide concentration. (d). Mechanism of herbicide release by proposed model for the $8 \mathrm{~g} \cdot \mathrm{L}^{-1}$ herbicide concentration. 
Table 1: Parameters obtained from each model for the different concentrations of herbicide.

\begin{tabular}{lcccc}
\hline $\begin{array}{l}\text { Concentration } \\
\text { of Herbicide }\end{array}$ & $\begin{array}{c}\text { Korsmayers- } \\
\text { Peppas } \\
\text { Model }\end{array}$ & $\begin{array}{c}\text { Higuchi } \\
\text { Model }\end{array}$ & $\begin{array}{c}\text { Baker- } \\
\text { Londsdale } \\
\text { Model }\end{array}$ & $\begin{array}{c}\text { Weibull } \\
\text { Model }\end{array}$ \\
\hline 4 g. L $^{-1}$ & $\mathrm{R}^{2}=0.97$ & $\mathrm{R}^{2}=0.87$ & $\mathrm{R}^{2}=0.94$ & $\mathrm{R}^{2}=0.96$ \\
6 g. $\mathrm{L}^{-1}$ & $\mathrm{R}^{2}=0.90$ & $\mathrm{R}^{2}>0.99$ & $\mathrm{R}^{2}=0.95$ & $\mathrm{R}^{2}=0.87$ \\
$8 \mathrm{~g} . \mathrm{L}^{-1}$ & - & - & - & - \\
\hline
\end{tabular}

\section{References}

1. Silva Mdos S, Cocenza DS, Grillo R, de Melo NFS, Tonello PS, de Oliveira LC, et al. Paraquat-loaded alginate/chitosan nanoparticles: Preparation, characterization and soil sorption studies. Journal of Hazardous Materials. 2011;190(1-3):366374. DOI: http://dx.doi.org/10.1016/j.jhazmat.2011.03.057

2. Agostini de Moraes M, Cocenza DS, da Cruz Vasconcellos F, Fraceto LF, Beppu MM. Chitosan and alginate biopolymer membranes for remediation of contaminated water with herbicides. Journal of Environmental Management. 2013;131:222-227. DOI: http://dx.doi.org/10.1016/j.jenvman.2013.09.028

3. Sharma R, Bajpai J, Bajpai AK, Acharya S, Shrivastava RB, Shukla SK. Designing slow water-releasing alginate nanoreserviors for sustained irrigation in scanty rainfall areas. Carbohydrate Polymers. 2014;102:513-520. DOI: http://dx.doi.org/10.1016/j. carbpol.2013.11.059

4. El Bahri Z, Taverdet JL. Elaboration and characterisation of microparticles loaded by pesticide model. Powder Technology. 2007;172(1):3-40. DOI: http://dx.doi.org/10.1016/j. powtec. 2006.10 .036

5. Souza ELC, Foloni LL, Mantovani EC, Teixeira Filho J. Comportamento do tebuthiuron em solo de cultivo de cana-de-açúcar utilizando lisímetro de drenagem modificado. Planta Daninha. 2008;26(1):157163. DOI: http://dx.doi.org/10.1590/S0100-83582008000100016

6. Silva MRA, Trovó AG, Nogueira RFP. Degradation of the herbicide tebuthiuron using solar photo-Fenton process and ferric citrate complex at circumneutral $\mathrm{pH}$. Journal of Photochemistry and Photobiology A: Chemistry. 2007;191(2-3):187-192. DOI: http://dx.doi.org/10.1016/j.jphotochem.2007.04.022

7. Grillo R, Pereira AdoES, de Melo NFS, Porto RM, Feitosa LO, Tonello PS, et al. Controlled release system for ametryn using polymer microspheres: Preparation, characterization and release kinetics in water. Journal of Hazardous Materials. 2011;186(2-3):1645-1651. DOI: http://dx.doi.org/10.1016/j. jhazmat.2010.12.044

8. Mignon A, Snoeck D, D'Halluin K, Balcaen L, Vanhaecke F, Dubruel P, et al. Alginate biopolymers: Counteracting the impact of superabsorbent polymers on mortar strength. Construction and Building Materials. 2016;110:169-174. DOI: http://dx.doi. org/10.1016/j.conbuildmat.2016.02.033

9. Lacerda L, Parize AL, Fávere V, Laranjeira MCM, Stulzer HK. Development and evaluation of $\mathrm{pH}$-sensitive sodium alginate/ chitosan microparticles containing the antituberculosis drug rifampicin. Materials Science and Engineering: C. 2014;39:161167. DOI: http://dx.doi.org/10.1016/j.msec.2014.01.054
10. Dias FS, Queiroz DC, Nascimento RF, Lima MB. Um sistema simples para preparação de microesferas de quitosana. Química Nova. 2008;31(1):160-163. DOI: http://dx.doi.org/10.1590/ S0100-40422008000100028

11. Shi LES, Chen M, Xinf LY, Guo XF, Zhao LM. Chitosan nanoparticles as drug delivery carriers for biomedical engineering. Journal of the Chemical Society of Pakistan. 2011;33(6):929934.

12. Mendoza-Muñoz N, Piñón-Segundo E, Ganem-Quintanar A, Quintanar-Guerrero D. Preparación y evaluación in vitro de nanopartículas poliméricas biodegradables como agente de contraste para ultrasonido. Tip Revista Especializada en Ciencias Químico-Biológicas. 2007;10(1):14-20.

13. Silva MDS, Cocenza DS, De Melo NFS, Grillo R, Rosa AH, Fraceto LF. Nanopartículas de alginato como sistema de liberação para o herbicida clomazone. Química Nova. 2010;33(9):18681873. DOI: http://dx.doi.org/10.1590/S0100-40422010000900009

14. Jose S, Fangueiro JF, Smitha J, Cinu TA, Chacko AJ, Premaletha $\mathrm{K}$, et al. Predictive modeling on insulin release profile from cross-linked chitosan microspheres. European Journal of Medicinal Chemistry. 2013;60:249-253. DOI: http://dx.doi. org/10.1016/j.ejmech.2012.12.011

15. Dash S, Murthy PN, Nath L, Chowdhury P. Kinetic modeling on drug release from controlled drug delivery systems. Acta Poloniae Pharmaceutica. 2010;67(3):217-223

16. Strand KA, Boee A, Dalberg PS, Sikkeland T, Smidsroed O. Dynamic and static light scattering on aqueous solutions of sodium alginate. Macromolecules. 1982;15(2):570-579. DOI: http://dx.doi.org/10.1021/ma00230a070

17. Burey P, Bhandari BR, Howes T, Gidley MJ. Hydrocolloid gel particles: formation, characterization, and application. Critical Reviews in Food Science and Nutrition. 2008;48(5):361-377. DOI: http://dx.doi.org/10.1080/10408390701347801

18. McConaughy SD, Stroud PA, Boudreaux B, Hester RD, McCormick CL. Structural characterization and solution properties of a galacturonate polysaccharide derived from Aloe vera capable of in situ gelation. Biomacromolecules. 2008;9(2):472-480. DOI: 10.1021/bm7009653

19. Agrawal S, Ashokraj Y, Bharatam PV, Pillai O, Panchagnula R. Solid-state characterization of rifampicin samples and its biopharmaceutic relevance. European Journal of Pharmaceutical Sciences. 2004;22(2-3):127-144. DOI: http://dx.doi.org/10.1016/j. ejps.2004.02.011

20. Antonietti M, Landfester K. Polyreactions in miniemulsions. Progress in Polymer Science. 2002;27(4):689-757. DOI: http:// dx.doi.org/10.1016/S0079-6700(01)00051-X

21. Carbinatto FM, de Castro AD, Evangelista RC, Cury BSF. Insights into the swelling process and drug release mechanisms from cross-linked pectin/high amylose starch matrices. Asian Journal of Pharmaceutical Sciences. 2014;9(1):27-34. DOI: http://dx.doi.org/10.1016/j.ajps.2013.12.002

22. Cahyaningrum SE, Herdyastuti N, Qomariah N. Synthesis and Characterization of Chitosan- Alginate for Controlled Release of Isoniazid Drug. Indonesian Journal of Chemistry. 2015;15(1):16-21. 